\title{
Respiratory system involvement in inflammatory bowel diseases
}

The authors declare no financial disclosure

\begin{abstract}
Inflammatory bowel diseases are systemic disorders that can manifest in any location. The problem of respiratory system involvement is very important form clinical point of view. In the article we try to systematize the current knowledge on this topic.

Key words: inflammatory bowel diseases, Crohn's disease, ulcerative colitis, lung diseases, airways diseases
\end{abstract}

Adv. Respir. Med. 2017; 85: 161-168

\section{Introduction}

Inflammatory bowel disease (IBD) is a group of chronic inflammatory disorders of small and large intestine, characterised by relapsing pattern. IBD comprises ulcerative colitis (UC), Crohn's disease (CD) and a subgroup of colitis difficult to classify as either form. The IBD incidence rate in Europe is 35 per 100000 person-years and is constantly growing. It is estimated that $0.3 \%$ of the European population is affected by IBD. In most regions UC is more frequent than CD [1]. The pathogenesis of IBD is not fully understood. Genetic predisposition, environmental factors and abnormal immune processes are believed to be involved [2]. In 15-20\% of UC patients and $20-40 \%$ of CD patients, so-called extraintestinal manifestations (EIM) of IBD are present [3-7]. Most commonly, involvement of central and peripheral joints, skin, eyes and the hepatobiliary system is seen [3-7]. It is most probably related to the presence of circulating antibodies against a colonic epithelial antigen that is shared among these organs [8]. The evidence of other organs involvement is smaller; however, it seems that practically any organ can be affected. Involvement of the respiratory tract is rare, but remains an object of constant interest.

\section{Mechanisms of interaction between the gastrointestinal and respiratory tracts in IBD}

Respiratory tract diseases in patients suffering from IBD may result from the following:

1) incidental coexistence,

2) extraintestinal manifestation of IBD,

3) local complications of IBD: colobronchial or oesophagopulmonary fistulae,

4) side-effects of IBD treatment: infections, drug-induced pneumotoxicity

5) hypercoagulability: pulmonary embolism.

The hypothesis that IBD is associated with respiratory morbidity is based on both theoretical and practical grounds. The gastrointestinal tract and respiratory tract have common embryonic origin from the primitive foregut and share structural similarities [9]. The presence of the mucosa-associated lymphoid tissue in both systems seems to play a key role. It is believed that following mechanisms are involved in the development of inflammation within the respiratory system in the course of IBD: a) migration of activated lymphocytes from the gastrointestinal tract to the airways, which could shift inflammatory process from one site to the other, b) presence of unusual antigens such as bacteria, digestive enzymes, and dietary particles, appearing in circulation due to

Address for correspondence: Aneta Kacprzak, ${ }^{\text {st }}$ Department of Lung Diseases, National Tuberculosis and Lung Diseases Research Institute, Warsaw, Płocka 26, 01-138 Warszawa, e-mail: ankac2000@yahoo.coml 
loss of epithelial barrier function of the bowels, c) presence of antibodies and immune complexes that can cross-react in various areas of the human body $[2,10]$.

\section{Epidemiology}

There is no proper epidemiological investigation proving respiratory diseases to be EIM of IBD. Large original studies on EIM in IBD either do not mention such relationship or report it as a very small percentage of patients [4-6, 11, 12]. On the other hand, there is a large number of case reports that suggest existence of the phenomenon. First such reports appeared in the second half of the $20^{\text {th }}$ century $[13,14]$ and hundreds have been published since then [15-18]. It is believed that gut-lung communication is bidirectional, so two ways of approach to the subject can be found in the literature. One focuses on the respiratory tract diseases occurrence in IBD patients, and the other one on IBD occurrence in patients with respiratory diseases.

Retrospective analysis conducted by Raj et al. [19] seems to be one of the most noteworthy in terms of epidemiology. Among 2192 patients with airways disease seen in one chest clinic, they found 37 (1.7\%) patients with histologically confirmed diagnosis of IBD. Nine (24\%) of them had asthma, another 9 (24\%) COPD, 8 (22\%) chronic non-productive cough alone, 7 (19\%) bronchiectasis, 4 (10\%) chronic bronchitis. When compared to data on local IBD prevalence, it appeared that there were significantly more cases of IBD among patients with airways diseases than it would be expected in a similar-sized general population — odds ratio (OR) was 4.26 for all IBD, 5.96 for CD, 4.21 for UC. The association was particularly strong with airways diseases associated with productive cough. IBD was more frequent in all patterns of airways diseases except asthma. There are, however, studies showing contrary results on asthma-IBD association. On the basis of administrative data from health databases, they show higher prevalence of asthma in both UC and CD patients [7], or higher prevalence of UC and CD in asthma patients group [7, 20, 21], compared to control groups. Bernstein et al. [7] found that the risk of asthma was $50-70 \%$ higher in their patients with UC and $30-40 \%$ higher in their patients with CD, compared to population-based controls. Data from the same studied population, but looked at in a different way, indicated that IBD risk in asthma patients is also higher than in the control group: prevalence ratio for UC was 1.56 and for CD 1.38. Brassard et al. [20] reported on the incidence of $\mathrm{CD}$ in asthma patients $27 \%$ higher than in the general population, the incidence of UC did not differ significantly from the one in the general population. The incidence of CD was also significantly, i.e. $55 \%$ higher in COPD patients in comparison to the control group. Association between asthma and IBD was also suggested by Hemminki et al. [21]. Another study that showed a significantly increased prevalence of respiratory symptoms in subjects with IBD was one by Birring et al. [22]. They compared the frequency of respiratory symptoms in 64 IBD patients and 124 healthy persons. The OR for breathlessness, sputum production and cough was 3.4, 2.5 and 1.8, respectively. Wheeze and nocturnal cough were equally prevalent in both groups. Patients with CD were 1.4-3.0 times more likely to report respiratory symptoms than patients with UC. Other studies showed that respiratory symptoms were reported by $26-48 \%$ of IBD patients, which was more frequent than in healthy people [23-27].

Various abnormalities in pulmonary function tests (PFT) in IBD patients have also been reported. Up to $58 \%$ of these patients had at least one abnormal value in PFT [23-28]. Impairment of diffusion lung capacity for carbon monoxide (DLCO) was most commonly found [23-28]. In one of the studies, a group of IBD patients had significantly lower mean DLCO and higher ratio of residual volume (RV) to total lung capacity (TLC) than a control group [23]. In another study, mean values of forced expiratory volume in one second $\left(\mathrm{FEV}_{1}\right)$, ratio of $\mathrm{FEV}_{1}$ to forced vital capacity (FVC), maximum mid-expiratory flow (MMEF), DLCO, and carbon monoxide transfer coefficient $\left(\mathrm{K}_{\mathrm{co}}\right)$ were lower in IBD patients than in healthy subjects [26]. Abnormalities in PFT could be found even in nonsmoking IBD patients with no history of respiratory tract disorder and with normal chest x-ray [28]. Bronchial hypersensitivity in provocation tests with methacholine was observed in $17-71 \%$ of IBD patients, more often than in control groups [29-31].

Abnormalities in high resolution computed tomography (HRCT) of the lungs were noticed in up to $64 \%$ of IBD patients, even in the absence of clinical symptoms of respiratory disease. Most prevalent findings included as follows: peribronchial thickness, bronchiectasis, air trapping, reticular pattern, ground glass opacifications, emphysema, nodular opacifications, mediastinal lymphadenopathy, parenchymal opacifications, and rarely pleural abnormalities [24, 26, 27, 32].

Sputum and bronchoalveolar lavage (BAL) fluid in IBD patients have also been investigated. 
Mohamed-Hussein et al. [25] found that induced sputum of UC patients contained significantly more lymphocytes and eosinophils compared to healthy volunteers. Other authors reported on higher percentage of sputum eosinophils but not lymphocytes in UC patients [33] and CD patients [34]. Fireman et al. [35], on the other hand, found significantly higher lymphocyte count in induced sputum of non-smoking and respiratory symptoms free CD patients than in controls; in $65 \%$ of their patients, the CD4/CD8 lymphocytes ratio was higher than 2.5. Bonniere et al. [36] compared BAL fluid of 22 patients with CD, free of clinical pulmonary symptoms and with normal chest roentgenograms, with 25 control subjects. Total number of cells in BAL fluid was identical, but percentages of lymphocytes were higher in patients than in controls. In $54 \%$ of the patients, bronchoalveolar lymphocyte count was above $18 \%$. There was no correlation between abnormal BAL findings and activity of the intestinal disease, presence of the disease at other locations, or PFT results. Karadag et al. [32] examined BAL fluid of 10 UC patients, all were free of respiratory symptoms and had normal chest $\mathrm{x}$-ray. Alterations of different types were found in $50 \%$ of them. In all patients with abnormal BAL, lymphocytes constituted more than $15 \%$ of cells. Transbronchial lung biopsy was available in all 10 patients, and it revealed the following: normal histology in 2 cases, lymphocytes accumulation in the interalveolar spaces and interstitial fibrosis in the remaining cases.

Another tool that has been used in research on latent respiratory tract involvement in the course of IBD was measurement of exhaled nitric oxide (eNO). This parameter is considered to be a marker of airway inflammation. At least three independent authors found increased eNO in IBD patients compared to control subjects [37-39].

There were few attempts to assess alveolar epithelial permeability in respiratory symptoms free, non-smoking IBD patients with the use of technetium-99m diethylene triamine penta acetic acid (Tc-99m DTPA) aerosol scintigraphy. The increased rate of DTPA clearance indicates inflammation or lung insults of any cause. In two of three published papers, a significantly higher alveolar epithelial permeability was reported in IBD patients compared to healthy people [40, 41]. In the third study, no evidence of abnormal lung permeability in patients with IBD was found [42].

\section{Respiratory tract involvement according to anatomic site}

\section{Airways diseases - larynx, trachea, bronchi, bronchioli}

According to published data, EIM of IBD can occur anywhere along the airways; however, large and medium-sized bronchi were the most common location - 39-50\% of published cases $[16,18,43]$. In $66 \%$ of IBD patients with coexisting bronchi disease, bronchiectasis was diagnosed [16]. Bronchiectasis associated with IBD may be more extensive and severe, compared to bronchiectasis related to other aetiology. The second common pathology was chronic bronchitis [15, 16, 18]. Productive cough with abundant amounts of purulent sputum dominated in both bronchiectasis and chronic bronchitis [14, 43-45]. Despite purulent character of the sputum, cultures were usually negative [14]. Increased percentage of neutrophils was seen in BAL fluid, and microscopic study of bronchial mucosal biopsy showed infiltrates rich in lymphocytes and plasmatic cells [43]. Bronchiectasis and chronic bronchitis seemed to occur more frequently in the course of UC than CD [16, 18, 43]. Some authors argued that chronic bronchitis associated with IBD responded well to inhaled glucocorticosteroids [43, 46].

A rare form of respiratory tract involvement is airway stenosis. It may occur at any level from the larynx to the segmental bronchi [16, 43, 47-49]. Clinical presentation in these cases included dyspnoea, fever, expectoration, stridor and/or wheeze [16, 43, 47-49]. Endoscopic studies revealed polypoid or pseudotumoural structures and/or circumferential inflammation obstructing the airway lumen. These lesions were friable and haemorrhagic [16, 43, 47-49]. Histological examination showed granulation tissue and mixed inflammation with domination of lymphocytes and plasma cells [43, 47-49]. Airway obstruction was very severe in some cases. Treatment was targeted at IBD control, it is based on glucocorticosteroids and aminosalicylates. In some cases a mechanical dilatation or laser ablation were necessary [16, 43, 47-49].

Diseases of the small airways were less frequent, they constituted $3-10 \%$ of all cases of respiratory diseases in IBD patients [18]. However, subclinical involvement detected by HRCT and PFT is believed to be more common [24, 27, 30, $32,50]$. Usual symptoms of bronchiolitis included dry or productive cough, progressive breathlessness, wheezes on auscultation. Changes on ima- 
ging studies of the lungs include the following: air-trapping, tree-in-bud opacifications, groundglass opacifications, mosaic pattern, centrilobular nodules [16, 18, 43]. Various histological patterns were present, namely non-specific fibrosing and stenosing chronic bronchiolitis, bronchiolitis obliterans, granulomatous bronchiolitis, diffuse panbronchiolitis [12, 18, 32, 43]. Response to glucocorticosteroids treatment also varied [18, 43].

\section{Parenchymal diseases}

A broad spectrum of lung parenchymal diseases was observed in IBD patients., i.e. organizing pneumonia - the most common, eosinophilic pneumonia, interstitial pneumonia with noncaseating granulomas, nonspecific interstitial pneumonia, desquamative interstitial pneumonia, pulmonary fibrosis, nodules [12, 15-18, 43, 51]. The main symptoms included exertional dyspnoea, dry or productive cough, fever, pleuritic chest pain. Bilateral crackling, rales and less frequently wheezing could be heard on chest auscultation. Respiratory failure was not rare, sometimes intubation and mechanical ventilation was needed. Radiologic studies revealed bilateral abnormalities of various types. The most common abnormalities in pulmonary function tests were decreased TLC and DLCO. The treatment consisted of systemic glucocorticosteroids. The prognosis was usually good, however, fatal outcomes have also been reported [12, 15-18, 43].

The coexistence of IBD and pulmonary sarcoidosis is a subject of special interest. Black et al. [16] found 53 such cases in the literature published up to the year 2007, so sarcoidosis would have been the most frequent form of the lung involvement if it had been considered an EIM of IBD. Sarcoidosis was diagnosed in both UC and $\mathrm{CD}$ patients. More attention is paid to sarcoidosis in CD because there are some similarities between them: the presence of noncaseating epithelioid granulomas, dominance of type 1 helper lymphocytes in the inflammatory process, interaction between genetic and environmental factors in the diseases pathomechanisms. Differential diagnosis between CD and gastro-intestinal sarcoidosis is very difficult. In UC, inflammatory process has a different characteristic, with type 2 helper lymphocytes playing a main role and mixed inflammatory infiltrations accumulating in crypt abscesses. Nevertheless, in 2009, the British researchers demonstrated that UC, but not CD, was more prevalent in the population of sarcoidosis patients compared to the general population [52]. Interestingly, serum angiotensin converting enzyme (sACE) activity in IBD patients was lower or the same as in the control group [36, 53, 54]. In the study confined to active IBD, sACE activity was significantly higher in UC patients compared to CD patients and healthy subjects, but was still significantly lower than in patients with acute sarcoidosis [55].

One of possible radiological presentations of pulmonary involvement in the course of IBD are lung nodules, sometimes with cavitations within them [43, 56-61]. Histopathological verification of such findings has revealed the following: necrobiotic nodules composed of sterile aggregates of neutrophils containing areas of necrosis most frequently, bronchiolitis obliterans with organizing pneumonia, noncaseating epithelioid granulomas, heterogeneous lymphoid infiltrations, interstitial fibrosis and deposits of amyloid A component. Most of the reported patients were treated with systemic glucocorticosteroids and/or infliximab, and regression of pulmonary nodules was observed during the follow-up. The spontaneous resolution of the pulmonary nodules was also seen in few patients. Resolution, either spontaneous or during treatment, was very slow in some cases [43, 56-61].

\section{Pleura}

Pleuritis is rare in the course of IBD. Usually, it accompanies parenchymal diseases or colobronchial fistulae. It may also be a part of serositis of unknown aetiology, in these cases pericarditis is present too [16, 43].

\section{Drug-related pulmonary toxicity}

The medications used for IBD treatment include as follows: a) anti-inflammatory drugs: aminosalicylates (sulphasalazine, mesalazine, olsalazine, balsalazide), glucocorticosteroids, b) immunosuppressants: azathioprine, 6-mercaptopurine, methotrexate, c) anti-TNF drugs: infliximab, adalimumab. All these medications, with the exception of glucocorticosteroids, are well known for their possible lung toxicity [62-71]. The assumed lung-toxicity manifests itself mostly as interstitial lung diseases such as eosinophilic pneumonia, organizing pneumonia, interstitial lung fibrosis, interstitial pneumonia with nonnecrotizing granulomas, not specified interstitial pneumonia, bronchiolitis [60-69]. Rarely drug-induced toxicity manifests itself as pleuritis [72-74]. There are no differences between symptoms and radiological features of the respiratory tract diseases appearing as a consequence of drug toxicity and in other circumstances [62-71]. 
There is no single test that could differentiate between drug - related and drug-unrelated pulmonary disorder, either. Factors in favour of a drug-induced pathology are the following: clear time relation between a medication commencement and a disease onset, the presence of blood eosinophilia, disease resolution after medication withdrawal. The literature indicates that the majority of reported lung diseases in IBD patients is suspected to be drug-related [17, 43]. The management of such complications requires the withdrawal of suspected medication. Systemic glucocorticosteroids are commonly used in addition [62, 67, 70]. It is always necessary to exclude infective aetiology in patients treated with immunosuppressants or biological drugs, tuberculosis and opportunistic pathogens should be also taken into consideration [75-80]. Lung complications of IBD treatment may be fatal $[62,67,70,77]$.

\section{Colobronchial fistulae}

Fistulae between the gastrointestinal tract and neighbouring structures can be seen in CD patients. There are several reports on oesophagobronchial [81-83], colobronchial (splenic flexure area) [84-88], and ileobronchial [89] fistulae. Clinical and radiological presentation was that of pneumonia, typically with pleural effusion and anaerobic flora on sputum culture. Surgical treatment was usually necessary. Pulmonary fistulae should be always considered in patients with CD and difficult to treat pneumonia [81-88].

\section{Thromboembolic disease}

IBD is a well documented risk factor for thromboembolic disease (TED), with strength similar to that of a cancer [90]. IBD doubles the risk of TED [91]. The risk is dependent on the activity of IBD, in active disease it is 8 times higher than in the general population [92]. TED is more prevalent in CD patients when the disease involves the colon, and in UC patients when the disease is more extensive [93]. The risk of TED recurrence after anticoagulant treatment completion is also increased [94]. The reason for higher TED risk in IBD remains obscure, it is believed to be complex. Beside the hypercoagulability related to inflammation, the role of various other acquired and congenital factors is postulated. There is no evidence for higher prevalence of thrombophilia in patients with IBD and TED, in comparison to IBD patients without TED [95]. The treatment of TED in IBD patients is the same as in the general population; however, it may be more challenging due to increased risk of gastrointestinal bleeding in IBD. The data on effectiveness and safety of chronic anticoagulation as a primary prophylaxis of TED in IBD is lacking.

\section{Time frame}

In most cases, IBD preceded onset of respiratory symptoms, in some patients they occurred concomitantly, and in others respiratory symptoms developed before IBD. The occurrence of IBD and respiratory disease may be separated by days or by decades [12, 14, 43, 45, 51]. Bronchial disorders usually developed after IBD diagnosis, while about $30 \%$ of bronchiolitis cases were recognised before IBD [16, 17]. Of special interest is development of bronchiectasis and chronic bronchitis after a colectomy; in 50-60\% of reported cases, it happened within a first year after the surgery [16, 18, 43]. Moreover, colectomy did not improve already existing respiratory symptoms $[14,51]$. There were also rare cases of interstitial lung disease appearing after colectomy for UC [96, 97].

Serositis, not related to drug toxicity, developed in most cases during IBD exacerbation or the first episode of the disease [43].

\section{Respiratory disease depending on IBD activity}

Few studies dealt with relationship between respiratory symptoms and activity of IBD. In the study by Birring et al. [22], there was a trend for those with active inflammatory bowel disease to report more symptoms, compared to those whose IBD was in remission. Yilmaz et al. [26] found association of increased respiratory symptom score with high endoscopic activity index in UC patients, but there was no correlation between respiratory symptoms and clinical activity of bowel disease. Alterations in PFT were more frequent in patients with active IBD as well [24, 28, 98]. Decrease in $\mathrm{FEV}_{1}, \mathrm{FVC}, \mathrm{FEV}_{1} / \mathrm{VC}$, MMEF, and DLCO was most commonly reported [25, 26, 28, 98], some authors also noticed increase in RV, RV/TLC, and functional residual capacity $[23,28,99]$ in active period of IBD, compared to a period of remission of the disease. No relationship was found between duration of IBD and pulmonary function test results [26]. Bronchial hyperresponsiveness on methacholine challenge was independent of activity, extent and time of duration of IBD [29-31]. Exhaled NO correlated positively with IBD activity [37-39], but no relation was found for alveolar epithelial per- 
meability measured with the use of Tc-99m DTPA aerosol scintigraphy [40, 41]. Data on relationship between IBD activity and chest HRCT picture are discrepant. Some researchers reported on more prevalent lung HRCT abnormalities in patients with active IBD compared to patients with IBD in remission [24], others were unable to find such correlation [26]. No dependency between IBD duration and alterations on chest HRCT scans was identified [26]. Connection with IBD activity was found neither for lymphocyte nor eosinophil count in sputum [25]. Differential cell count in BAL fluid was not associated with IBD activity either [32-36].

The analysis of numerous case reports and case series showed that respiratory symptoms could develop in association with IBD flare as well as during remission of the disease, in some patients concomitant exacerbations of bowel and respiratory symptoms were reported $[14,100]$.

\section{Summary}

The literature suggesting the respiratory involvement in the course of IBD is very rich; however, the proof that respiratory diseases are more prevalent in IBD patients than in the general population is still lacking. The awareness of possible respiratory complications in IBD patients should be present in clinical practice, as some of them may be very severe, even life-threatening. The lung toxicity of medications used for IBD should also be kept in mind, as it is believed to be responsible for most of respiratory complications in IBD patients.

\section{Conflict of interest}

The authors declare no conflict of interest.

\section{References:}

1. Burisch J, Jess T, Martinato M, et al. ECCO-EpiCom. The burden of inflammatory bowel disease in Europe. J Crohns Colitis. 2013; 7(4): 322-337, doi: 10.1016/j.crohns.2013.01.010, indexed in Pubmed: 23395397.

2. Bamias G, Nyce MR, De La Rue SA, et al. American College of Physicians, American Physiological Society. New concepts in the pathophysiology of inflammatory bowel disease. Ann Intern Med. 2005; 143(12): 895-904, indexed in Pubmed: 16365470 .

3. Lakatos L, Pandur T, David G, et al. Association of extraintestinal manifestations of inflammatory bowel disease in a province of western Hungary with disease phenotype: results of a 25-year follow-up study. World J Gastroenterol. 2003; 9(10): 2300-2307, indexed in Pubmed: 14562397.

4. Edwards FC, Truelove SC. The course and prognosis of ulcerative colitis. Gut. 1963; 4: 299-315, indexed in Pubmed: 14084741.

5. Zippi M, Corrado C, Pica R, et al. Extraintestinal manifestations in a large series of Italian inflammatory bowel disease patients. World J Gastroenterol. 2014; 20(46): 17463-17467, doi: $\underline{10.3748 / w j g . v 20 . i 46.17463}$, indexed in Pubmed: 25516659.
6. Bernstein CN, Blanchard JF, Rawsthorne P, et al. The prevalence of extraintestinal diseases in inflammatory bowel disease: a population-based study. Am J Gastroenterol. 2001; 96(4) 1116-1122, doi: 10.1111/j.1572-0241.2001.03756.x, indexed in Pubmed: 11316157.

7. Bernstein CN, Wajda A, Blanchard JF. The clustering of other chronic inflammatory diseases in inflammatory bowel disease: a population-based study. Gastroenterology. 2005; 129(3): 827-836, doi: 10.1053/j.gastro.2005.06.021, indexed in Pubmed: 16143122 .

8. Bhagat S, Das KM. A shared and unique peptide in the human colon, eye, and joint detected by a monoclonal antibody. Gastroenterology. 1994; 107(1): 103-108, indexed in Pubmed: 8020652.

9. Ornitz DM, Yin Y. Signaling networks regulating development of the lower respiratory tract. Cold Spring Harb Perspect Biol. 2012; 4(5), doi: 10.1101/cshperspect.a008318, indexed in Pubmed: 22550231 .

10. Mestecky J. The common mucosal immune system and current strategies for introduction of immune responses in external secretions. J Clin Immunol . 1987; 74: 265-267.

11. Rogers BH, Clark LM, Kirsner JB. The epidemiologic and demographic characteristics of inflammatory bowel disease: an analysis of a computerized file of 1400 patients. J Chronic Dis. 1971; 24(12): 743-773, indexed in Pubmed: $\underline{5146188 .}$.

12. Casey MB, Tazelaar HD, Myers JL, et al. Noninfectious lung pathology in patients with Crohn's disease. Am J Surg Pathol. 2003; 27(2): 213-219, indexed in Pubmed: 12548168.

13. Isenberg JI, Goldstein H, Korn AR, et al. Pulmonary vasculitis-an uncommon complication of ulcerative colitis. Report of a case. N Engl J Med. 1968; 279(25): 1376-1377, doi: 10.1056/ NEJM196812192792506, indexed in Pubmed: 5697529.

14. Kraft SC, Earle RH, Roesler M, et al. Unexplained bronchopulmonary disease with inflammatory bowel disease. Arch Intern Med. 1976; 136(4): 454-459, indexed in Pubmed: 1267553.

15. Storch I, Sachar D, Katz S. Pulmonary manifestations of inflammatory bowel disease. Inflamm Bowel Dis. 2003; 9(2): 104-115, indexed in Pubmed: 12769444.

16. Black H, Mendoza M, Murin S. Thoracic manifestations of inflammatory bowel disease. Chest. 2007; 131(2): 524-532, doi: 10.1378/chest.06-1074, indexed in Pubmed: 17296657.

17. Ji XQ, Wang LX, Lu DG. Pulmonary manifestations of inflammatory bowel disease. World J Gastroenterol. 2014; 20(37): 13501-13511, doi: 10.3748/wig.v20.i37.13501, indexed in Pubmed: 25309080.

18. Papanikolaou I, Kagouridis K, Papiris SA. Patterns of airway involvement in inflammatory bowel diseases. World J Gastrointest Pathophysiol. 2014; 5(4): 560-569, doi: 10.4291/wigp. v5.i4.560, indexed in Pubmed: 25400999.

19. Raj AA, Birring SS, Green R, et al. Prevalence of inflammatory bowel disease in patients with airways disease. Respir Med. 2008; 102(5): 780-785, doi: 10.1016/j.rmed.2007.08.014, indexed in Pubmed: 18321696.

20. Brassard P, Vutcovici M, Ernst P, et al. Increased incidence of inflammatory bowel disease in Québec residents with airway diseases. Eur Respir J. 2015; 45(4): 962-968, doi: 10.1183/09031936.00079414, indexed in Pubmed: 25406447.

21. Hemminki K, Li X, Sundquist J, et al. Subsequent autoimmune or related disease in asthma patients: clustering of diseases or medical care? Ann Epidemiol. 2010; 20(3): 217-222, doi: 10.1016/j.annepidem.2009.11.007, indexed in Pubmed: $\underline{20036578}$.

22. Birring SS, Morgan AJ, Prudon B, et al. Respiratory symptoms in patients with treated hypothyroidism and inflammatory bowel disease. Thorax. 2003; 58(6): 533-536, indexed in Pubmed: 12775870 .

23. Douglas JG, McDonald CF, Leslie MJ, et al. Respiratory impairment in inflammatory bowel disease: does it vary with disease activity? Respir Med. 1989; 83(5): 389-394, indexed in Pubmed: 2616823.

24. Songür N, Songür Y, Tüzün M, et al. Pulmonary function tests and high-resolution CT in the detection of pulmonary involvement in inflammatory bowel disease. J Clin Gastroenterol. 2003; 37(4): 292-298, indexed in Pubmed: 14506385.

25. Aar M-H, Nas M, Mear I. Changes in pulmonary function in patients with ulcerative colitis. Respir Med. 2007; 101(5): 
977-982, doi: 10.1016/j.rmed.2006.09.005, indexed in Pubmed: 17049827.

26. Yilmaz A, Yilmaz Demirci N, Hoşgün D, et al. Pulmonary involvement in inflammatory bowel disease. World J Gastroenterol. 2010; 16(39): 4952-4957, indexed in Pubmed: 20954282.

27. Desai D, Patil S, Udwadia Z, et al. Pulmonary manifestations in inflammatory bowel disease: a prospective study. Indian J Gastroenterol. 2011; 30(5): 225-228, doi: 10.1007/s12664-0110129-1, indexed in Pubmed: 21935713.

28. Ateş F, Karincaoğlu M, Hacievlıyagıl SS, et al. Alterations in the pulmonary function tests of inflammatory bowel diseases. Turk J Gastroenterol. 2011; 22(3): 293-299, indexed in Pubmed: 21805420.

29. Louis E, Louis R, Drion V, et al. Increased frequency of bronchial hyperresponsiveness in patients with inflammatory bowel disease. Allergy. 1995; 50(9): 729-733, indexed in Pubmed: 8546267.

30. Mansi A, Cucchiara S, Greco L, et al. Bronchial hyperresponsiveness in children and adolescents with Crohn's disease. Am J Respir Crit Care Med. 2000; 161(3 Pt 1): 1051-1054, doi: 10.1164/ajrccm.161.3.9906013, indexed in Pubmed: 10712362.

31. Ceyhan BB, Karakurt S, Cevik H, et al. Bronchial hyperreactivity and allergic status in inflammatory bowel disease. Respiration. 2003; 70(1): 60-66, doi: 68407, indexed in Pubmed: 12584393.

32. Karadag F, Ozhan MH, Akçiçek E, et al. Is it possible to detect ulcerative colitis-related respiratory syndrome early? Respirology. 2001; 6(4): 341-346, indexed in Pubmed: 11844126.

33. Fireman E, Masarwy F, Groisman G, et al. Induced sputum eosinophilia in ulcerative colitis patients: the lung as a mirror image of intestine? Respir Med. 2009; 103(7): 1025-1032, doi: 10.1016/j.rmed.2009.01.016, indexed in Pubmed: 19230639.

34. Louis E, Louis R, Shute J, et al. Bronchial eosinophilic infiltration in Crohn's disease in the absence of pulmonary disease. Clin Exp Allergy. 1999; 29(5): 660-666, indexed in Pubmed: 10231326.

35. Fireman Z, Osipov A, Kivity S, et al. The use of induced sputum in the assessment of pulmonary involvement in Crohn's disease. Am J Gastroenterol. 2000; 95(3): 730-734, doi: 10.1111/j.1572-0241.2000.01843.x, indexed in Pubmed: 10710066.

36. Bonniere $\mathrm{P}$, Wallaert B, Cortot A, et al. Latent pulmonary involvement in Crohn's disease: biological, functional, bronchoalveolar lavage and scintigraphic studies. Gut. 1986; 27(8): 919-925, indexed in Pubmed: 3015749.

37. Koek GH, Verleden GM, Evenepoel P, et al. Activity related increase of exhaled nitric oxide in Crohn's disease and ulcerative colitis: a manifestation of systemic involvement? Respir Med. 2002; 96(7): 530-535, indexed in Pubmed: 12194639.

38. Ozyilmaz E, Yildirim B, Erbas G, et al. Value of fractional exhaled nitric oxide (FE NO) for the diagnosis of pulmonary involvement due to inflammatory bowel disease. Inflamm Bowel Dis. 2010; 16(4): 670-676, doi: 10.1002/ibd.21085, indexed in Pubmed: 19705414.

39. Malerba M, Ragnoli B, Buffoli L, et al. Exhaled nitric oxide as a marker of lung involvement in Crohn's disease. Int J Immunopathol Pharmacol. 2011; 24(4): 1119-1124, doi: 10.1177/039463201102400434, indexed in Pubmed: 22230422.

40. Gursoy S, Guven K, Kula M, et al. Subclinical alveolar involvement in ulcerative colitis. Inflamm Bowel Dis. 2005; 11(4): 372-375, indexed in Pubmed: 15803027.

41. Adenis A, Colombel JF, Lecouffe P, et al. Increased pulmonary and intestinal permeability in Crohn's disease. Gut. 1992; 33(5): 678-682, indexed in Pubmed: 1612487.

42. Robertson DA, Taylor N, Sidhu H, et al. Pulmonary permeability in coeliac disease and inflammatory bowel disease. Digestion. 1989; 42(2): 98-103, indexed in Pubmed: 2670648.

43. Camus P, Piard F, Ashcroft T, et al. The lung in inflammatory bowel disease. Medicine (Baltimore). 1993; 72(3): 151-183, indexed in Pubmed: 8502168.

44. Higenbottam T, Cochrane GM, Clark TJ, et al. Bronchial disease in ulcerative colitis. Thorax. 1980; 35(8): 581-585, indexed in Pubmed: 7444824

45. Spira A, Grossman R, Balter M. Large airway disease associated with inflammatory bowel disease. Chest. 1998; 113(6): 1723-1726, indexed in Pubmed: 9631822.
46. Hamada S, Ito Y, Imai S, et al. Effect of inhaled corticosteroid therapy on CT scan-estimated airway dimensions in a patient with chronic bronchitis related to ulcerative colitis. Chest. 2011; 139(4): 930-932, doi: 10.1378/chest.10-1105, indexed in Pubmed: 21467060 .

47. Kuźniar T, Sleiman C, Brugière O, et al. Severe tracheobronchial stenosis in a patient with Crohn's disease. Eur Respir J. 2000; 15(1): 209-212, indexed in Pubmed: 10678648.

48. Plataki M, Tzortzaki E, Lambiri I, et al. Severe airway stenosis associated with Crohn's disease: case report. BMC Pulm Med. 2006; 6: 7, doi: 10.1186/1471-2466-6-7, indexed in Pubmed: 16603056.

49. Lu DG, Ji XQ, Zhao Qi, et al. Tracheobronchial nodules and pulmonary infiltrates in a patient with Crohn's disease. World J Gastroenterol. 2012; 18(39): 5653-5657, doi: 10.3748/wjg.v18. $\underline{\text { i39.5653 }}$, indexed in Pubmed: 23112563.

50. Tzanakis N, Samiou M, Bouros D, et al. Small airways function in patients with inflammatory bowel disease. Am J Respir Crit Care Med. 1998; 157(2): 382-386, doi: 10.1164/ajrccm.157.2.97-04075, indexed in Pubmed: 9476847.

51. Mahadeva R, Walsh G, Flower CD, et al. Clinical and radiological characteristics of lung disease in inflammatory bowel disease. Eur Respir J. 2000; 15(1): 41-48, indexed in Pubmed: 10678619.

52. Rajoriya N, Wotton CJ, Yeates DGR, et al. Immune-mediated and chronic inflammatory disease in people with sarcoidosis: disease associations in a large UK database. Postgrad Med J. 2009; 85(1003): 233-237, doi: 10.1136/pgmj.2008.067769, indexed in Pubmed: 19520873.

53. Studdy P, Bird R, James DG. Serum angiotensin-converting enzyme (SACE) in sarcoidosis and other granulomatous disorders. Lancet. 1978; 2(8104-5): 1331-1334, indexed in Pubmed: $\underline{82838}$.

54. Matsuda T, Suzuki J, Furuya K, et al. Serum angiotensin I-converting enzyme is reduced in Crohn's disease and ulcerative colitis irrespective of genotype. Am J Gastroenterol. 2001; 96(9): 2705-2710, doi: 10.1111/j.1572-0241.2001.03945.x, indexed in Pubmed: 11569699.

55. Letizia C, D’Ambrosio C, Agostini D, et al. Serum angiotensin converting enzyme activity in Crohn's disease and ulcerative colitis. Ital J Gastroenterol. 1993; 25(1): 23-25, indexed in Pubmed: $\underline{8381313}$.

56. Beer TW, Edwards CW. Pulmonary nodules due to reactive systemic amyloidosis (AA) in Crohn's disease. Thorax. 1993; 48(12): 1287-1288, indexed in Pubmed: 8303644.

57. Alrashid AI, Brown RD, Mihalov ML, et al. Crohn's disease involving the lung: resolution with infliximab. Dig Dis Sci. 2001; 46(8): 1736-1739, indexed in Pubmed: 11508676.

58. Gill KRS, Mahadevan U. Infliximab for the treatment of metastatic hepatic and pulmonary Crohn's disease. Inflamm Bowel Dis. 2005; 11(2): 210-212, indexed in Pubmed: 15677920.

59. Nguyen T, Shepela C, Patnaik M, et al. Pulmonary nodules as an extra-intestinal manifestation of inflammatory bowel disease: a case series and review of the literature. Dig Dis Sci. 2009; 54(5): 1135-1140, doi: 10.1007/s10620-008-0442-4, indexed in Pubmed: 18716869.

60. Warwick G, Leecy T, Silverstone E, et al. Pulmonary necrobiotic nodules: a rare extraintestinal manifestation of Crohn's disease. Eur Respir Rev. 2009; 18(111): 47-50, doi: 10.1183/09059180.00011114, indexed in Pubmed: 20956123.

61. Carrascosa MF, Salcines-Caviedes JR, Millán MV, et al. Pulmonary nodules as respiratory manifestation of inflammatory bowel disease: case report and review. Inflamm Bowel Dis. 2011; 17(8): E99-101, doi: 10.1002/ibd.21762, indexed in Pubmed: 21604333 .

62. Parry SD, Barbatzas C, Peel ET, et al. Sulphasalazine and lung toxicity. Eur Respir J. 2002; 19(4): 756-764, indexed in Pubmed: 11999006.

63. Foster RA, Zander DS, Mergo PJ, et al. Mesalamine-related lung disease: clinical, radiographic, and pathologic manifestations. Inflamm Bowel Dis. 2003; 9(5): 308-315, indexed in Pubmed: 14555914.

64. Kacprzak A, Siemion-Szcześniak I, Szturmowicz M, et al. Pulmonary pathology in patients with ulcerative colitis treated with mesalazine--a challenging and complex diagnostic problem. Case series and literature review. Pneumonol Alergol 
Pol. 2014; 82(4): 368-376, doi: 10.5603/PiAP.2014.0047, indexed in Pubmed: 24964241.

65. Ananthakrishnan AN, Attila T, Otterson MF, et al. Severe pulmonary toxicity after azathioprine/6-mercaptopurine initiation for the treatment of inflammatory bowel disease. J Clin Gastroenterol. 2007; 41(7): 682-688, doi: 10.1097/01. mcg.0000225577.81008.ee, indexed in Pubmed: 17667053.

66. Nagy F, Molnar T, Makula E, et al. A case of interstitial pneumonitis in a patient with ulcerative colitis treated with azathioprine. World J Gastroenterol. 2007; 13(2): 316-319, indexed in Pubmed: 17226917.

67. Imokawa S, Colby TV, Leslie KO, et al. Methotrexate pneumonitis: review of the literature and histopathological findings in nine patients. Eur Respir J. 2000; 15(2): 373-381, indexed in Pubmed: 10706507.

68. Margagnoni G, Papi V, Aratari A, et al. Methotrexate-induced pneumonitis in a patient with Crohn's disease. J Crohns Colitis. 2010; 4(2): 211-214, doi: 10.1016/j.crohns.2009.11.007. indexed in Pubmed: 21122509.

69. Riegert-Johnson DL, Godfrey JA, Myers JL, et al. Delayed hypersensitivity reaction and acute respiratory distress syndrome following infliximab infusion. Inflamm Bowel Dis. 2002; 8(3): 186-191, indexed in Pubmed: 11979139.

70. Ramos-Casals M, Brito-Zerón P, Muñoz S, et al. Autoimmune diseases induced by TNF-targeted therapies: analysis of 233 cases. Medicine (Baltimore). 2007; 86(4): 242-251, doi: $10.1097 /$ MD.0b013e3181441a68, indexed in Pubmed: 17632266.

71. Reid JD, Bressler B, English J. A case of adalimumab-induced pneumonitis in a 45-year-old man with Crohn's disease. Can Respir J. 2011; 18(5): 262-264, indexed in Pubmed: 21969926.

72. Hamadeh M, Atkinson J, Smith L. Sulfasalazine-induced Pulmonary Disease. Chest. 1992; 101(4): 1033-1037, doi: 10.1378/ chest.101.4.1033.

73. Sesin GP, Mucciardi N, Almeida S. Mesalamine-associated pleural effusion with pulmonary infiltration. Am J Health Syst Pharm. 1998; 55(21): 2304-2305, indexed in Pubmed: 9825882.

74. Trisolini R, Dore R, Biagi F, et al. Eosinophilic pleural effusion due to mesalamine. Report of a rare occurrence. Sarcoidosis Vasc Diffuse Lung Dis. 2000; 17(3): 288-291, indexed in Pubmed: 11033846 .

75. Keane J, Gershon S, Wise RP, et al. Tuberculosis associated with infliximab, a tumor necrosis factor alpha-neutralizing agent. N Engl J Med. 2001; 345(15): 1098-1104, doi: 10.1056/ NEJMoa011110, indexed in Pubmed: 11596589.

76. Kaur N, Mahl TC. Pneumocystis jiroveci (carinii) pneumonia after infliximab therapy: a review of 84 cases. Dig Dis Sci. 2007; 52(6): 1481-1484, doi: 10.1007/s10620-006-9250-x, indexed in Pubmed: 17429728.

77. Colombel JF, Loftus EV, Tremaine WJ, et al. The safety profile of infliximab in patients with Crohn's disease: the Mayo clinic experience in 500 patients. Gastroenterology. 2004; 126(1): 19-31, indexed in Pubmed: 14699483.

78. Tsiodras S, Samonis G, Boumpas DT, et al. Fungal infections complicating tumor necrosis factor alpha blockade therapy. Mayo Clin Proc. 2008; 83(2): 181-194, indexed in Pubmed: 18241628.

79. Cohen RD, Bowie WR, Enns R, et al. Pulmonary actinomycosis complicating infliximab therapy for Crohn's disease. Thorax. 2007; 62(11): 1013-1014, doi: 10.1136/thx.2006.075150, indexed in Pubmed: 17965080.

80. Toruner M, Loftus EV, Harmsen WS, et al. Risk factors for opportunistic infections in patients with inflammatory bowel disease. Gastroenterology. 2008; 134(4): 929-936, doi: 10.1053/i.gastro.2008.01.012, indexed in Pubmed: 18294633.

81. Ghahremani GG, Gore RM, Breuer RI, et al. Esophageal manifestations of Crohn's disease. Gastrointest Radiol. 1982; 7(3): 199-203, indexed in Pubmed: 7106483.
82. Cynn WS, Chon H, Gureghian PA, et al. Crohn's disease of the esophagus. Am J Roentgenol Radium Ther Nucl Med. 1975; 125(2): 359-364, indexed in Pubmed: 1200234.

83. Steel A, Dyer NH, Matthews HR. Cervical Crohn's disease with oesophago-pulmonary fistula. Postgrad Med J. 1988; 64(755): 706-709, indexed in Pubmed: 3251228.

84. Karmy-Jones R, Chagpar A, Vallieres E, et al. Colobronchial fistula due to Crohn's disease. Ann Thorac Surg. 1995; 60(2): 446-448, indexed in Pubmed: 7646116.

85. Mera A, Sugimoto M, Fukuda K, et al. Crohn's disease associated with colo-bronchial fistula. Intern Med. 1996; 35(12): 957-960, indexed in Pubmed: 9030994.

86. Domej W, Kullnig P, Petritsch W, et al. Colobronchial fistula: a rare complication of Crohn's colitis. Am Rev Respir Dis. 1990; 142(5): 1225-1227, doi: 10.1164/ajrccm/142.5.1225, indexed in Pubmed: 2240849 .

87. Singh D, Cole JC, Cali RL, et al. Colobronchial fistula: an unusual complication of Crohn's disease. Am J Gastroenterol. 1994; 89(12): 2250-2252, indexed in Pubmed: 7977257.

88. Leichtling JJ, Garlock JH. Granulomatous colitis complicated by gastrocolic, duodenocolic, and colopulmonic fistulas. Gastroenterology. 1962; 43: 151-165, indexed in Pubmed: 14463834

89. Gumbo T, Rice TW, Mawhorter S. Recurrent pneumonia from an ileobronchial fistula complicating Crohn's disease. J Clin Gastroenterol. 2001; 32(4): 365-367, indexed in Pubmed: 11276288.

90. Konstantinides SV, Torbicki A, Agnelli G, et al. Task Force for the Diagnosis and Management of Acute Pulmonary Embolism of the European Society of Cardiology (ESC). 2014 ESC guidelines on the diagnosis and management of acute pulmonary embolism. Eur Heart J. 2014; 35(43): 3033-69, 3069a, doi: 10.1093/eurheartj/ehu283, indexed in Pubmed: 25173341.

91. Yuhara H, Steinmaus C, Corley D, et al. Meta-analysis: the risk of venous thromboembolism in patients with inflammatory bowel disease. Aliment Pharmacol Ther. 2013; 37(10): 953-962, doi: 10.1111/apt.12294, indexed in Pubmed: 23550660.

92. Grainge MJ, West J, Card TR. Venous thromboembolism during active disease and remission in inflammatory bowel disease: a cohort study. Lancet. 2010; 375(9715): 657-663, doi: 10.1016/ S0140-6736(09)61963-2, indexed in Pubmed: 20149425.

93. Solem CA, Loftus EV, Tremaine WJ, et al. Venous thromboembolism in inflammatory bowel disease. Am J Gastroenterol. 2004; 99(1): 97-101, indexed in Pubmed: 14687149.

94. Novacek G, Weltermann A, Sobala A, et al. Inflammatory bowel disease is a risk factor for recurrent venous thromboembolism. Gastroenterology. 2010; 139(3): 779-87, 787.e1, doi: 10.1053/j.gastro.2010.05.026, indexed in Pubmed: 20546736.

95. Grip O, Svensson PJ, Lindgren S. Inflammatory bowel disease promotes venous thrombosis earlier in life. Scand J Gastroenterol. 2000; 35(6): 619-623, indexed in Pubmed: 10912662.

96. Balestra DJ, Balestra ST, Wasson JH. Ulcerative colitis and steroid-responsive, diffuse interstitial lung disease. A trial of $\mathrm{N}=$ 1. JAMA. 1988; 260(1): 62-64, indexed in Pubmed: 3379724.

97. Marten K, Fend F, Hautmann H, et al. Case report: Fatal acute exacerbation of usual interstitial pneumonia in ulcerative colitis. Br J Radiol. 2005; 78(932): 762-766, doi: 10.1259 bjr/95651807, indexed in Pubmed: 16046433.

98. Marvisi M, Borrello PD, Brianti M, et al. Changes in the carbon monoxide diffusing capacity of the lung in ulcerative colitis. Eur Respir J. 2000; 16(5): 965-968, indexed in Pubmed: 11153600.

99. Pasquis P, Colin R, Denis P, et al. Transient pulmonary impairment during attacks of Crohn's disease. Respiration. 1981 41(1): 56-59, indexed in Pubmed: 7244392.

100.Forrest JA, Shearman DJ. Pulmonary vasculitis and ulcerative colitis. Am J Dig Dis. 1975; 20(5): 482-486, indexed in Pubmed: $\underline{1130374}$. 